\title{
Towards Atomic Level Understanding of Transition Alumina Phases and Their Phase Transformations
}

\author{
L. Kovarik ${ }^{1}$, M. Bowden ${ }^{1}$, D. Shi ${ }^{2}$, A. Anderson ${ }^{1}$, Jianzhi Hu², J. Szanyi ${ }^{2}$, J. H. Kwak ${ }^{3}$, C.H.F. \\ Peden $^{2}$ \\ ${ }^{1}$ Environmental Molecular Sciences Laboratory, Pacific Northwest National Laboratory, P.O. \\ Box 999, Richland, Washington USA \\ ${ }^{2}$ Institute for Integrated Catalysis, Pacific Northwest National Laboratory, P.O. Box 999, \\ Richland, Washington USA \\ ${ }^{3}$ School of Nanobiotechnology \& Chemical Engineering, UNIST, Ulsan 689-798, Korea
}

Transition $\mathrm{Al}_{2} \mathrm{O}_{3}$ derived from dehydration of $\mathrm{Al}$ hydroxides are highly complex materials with a significant degree of inherent structural disorder. The way in which the disorder is manifested for various heat treatment conditions and for various hydroxide precursors is a highly relevant topic in catalysis, with important implications for rationalization of unique surface chemistry and catalytic behavior of these materials [1]. When heat-treated at relatively high temperatures $\left(>900^{\circ} \mathrm{C}\right)$, the complexity of the microstructure is generally associated with the polymorphs of $\delta-\mathrm{Al}_{2} \mathrm{O}_{3}$ and $\theta-\mathrm{Al}_{2} \mathrm{O}_{3}$, which form in closely inter-growing structures. This has been a main issue in their reliable characterization, and there are currently none or only poorly fitting crystallographic models available. Similarly, the stability of these polymorphs remains poorly understood and actively studied [2].

In this work we address the structural nature of $\delta-\mathrm{Al}_{2} \mathrm{O}_{3}$ and $\theta-\mathrm{Al}_{2} \mathrm{O}_{3}$, and the mode of their phase transformations using combination of in-situ and ex-situ imaging and spectroscopy techniques. The current work mainly relies on the use of HAADF Scanning Transmission Electron Microscopy imaging, XRD, high-resolution NMR and DFT calculations. The HAADF STEM observations were performed with a probe corrected FEI Titan 80-300, and the thermal treatment was performed under in-situ heating conditions inside the TEM with Aduro Protochips heating holder at $900-1100{ }^{\circ} \mathrm{C}$.

Figure 1 shows structural and morphological changes that occur during heat-treatment of transition $\mathrm{Al}_{2} \mathrm{O}_{3}$ particles. The in-situ observations enabled us to characterize the evolution of microstructure across several length scales, ranging from macro-scale porosity down to crystallographic level. At the crystallographic level, it is found that the defective nature of the microstructure is due to intergrowth from number structural variants that evolve concurrently during the thermal treatment. The structure of $\delta-\mathrm{Al}_{2} \mathrm{O}_{3}$ itself is fund to be a highly complex, lacking a long-range periodicity and requiring a rationalization in terms of several closely related crystallographic variants. The two main variants are identified as $\delta_{1}-\mathrm{Al}_{2} \mathrm{O}_{3}$ and $\delta_{2}-\mathrm{Al}_{2} \mathrm{O}_{3}$. Full crystallographic description was obtained on the basis of quantitative analysis of HAADF STEM images from a number of low indexed zones, as shown in Fig.1(f,g) and XRD analysis. Analogous characterization effort has been performed for $\theta-\mathrm{Al}_{2} \mathrm{O}_{3}$.

The validity of derived structures was evaluated with NMR measurements and DFT based modeling. It will be shown how energetic degeneracy among the various transition alumina leads to complex intergrowths. In Fig.1(h) we compare the stability of the newly derived $\delta_{1}-\mathrm{Al}_{2} \mathrm{O}_{3}$ and $\delta_{2}-\mathrm{Al}_{2} \mathrm{O}_{3}$ with $\gamma-\mathrm{Al}_{2} \mathrm{O}_{3}, \theta-\mathrm{Al}_{2} \mathrm{O}_{3}$, and the thermodynamically stable $\alpha-\mathrm{Al}_{2} \mathrm{O}_{3}$. In the final part of this talk, we describe the evolution of transition $\mathrm{Al}_{2} \mathrm{O}_{3}$ during thermal treatment, and discuss the mode of their phase transformations [4]. 
References

[1] G. Busca, Catalysis Today, (2013), p.1-12.

[2] I. Levin \& D. Brandon, Journal of the American Ceramic Society, 81(8), (1998), p.19952012.

[3] Kovarik, L., Bowden, M., Genc, A., Szanyi, J., Peden, C. H. F., \& Kwak, J. H. (2014). The Journal of Physical Chemistry C, 118(31), (2014), p.18051-18058.

[4] This research is part of the Chemical Imaging Initiative at Pacific Northwest National Laboratory. The work was conducted in the William R. Wiley Environmental Molecular Sciences Laboratory (EMSL), a national scientific user facility sponsored by DOE's Office of Biological and Environmental Research and located at PNNL.
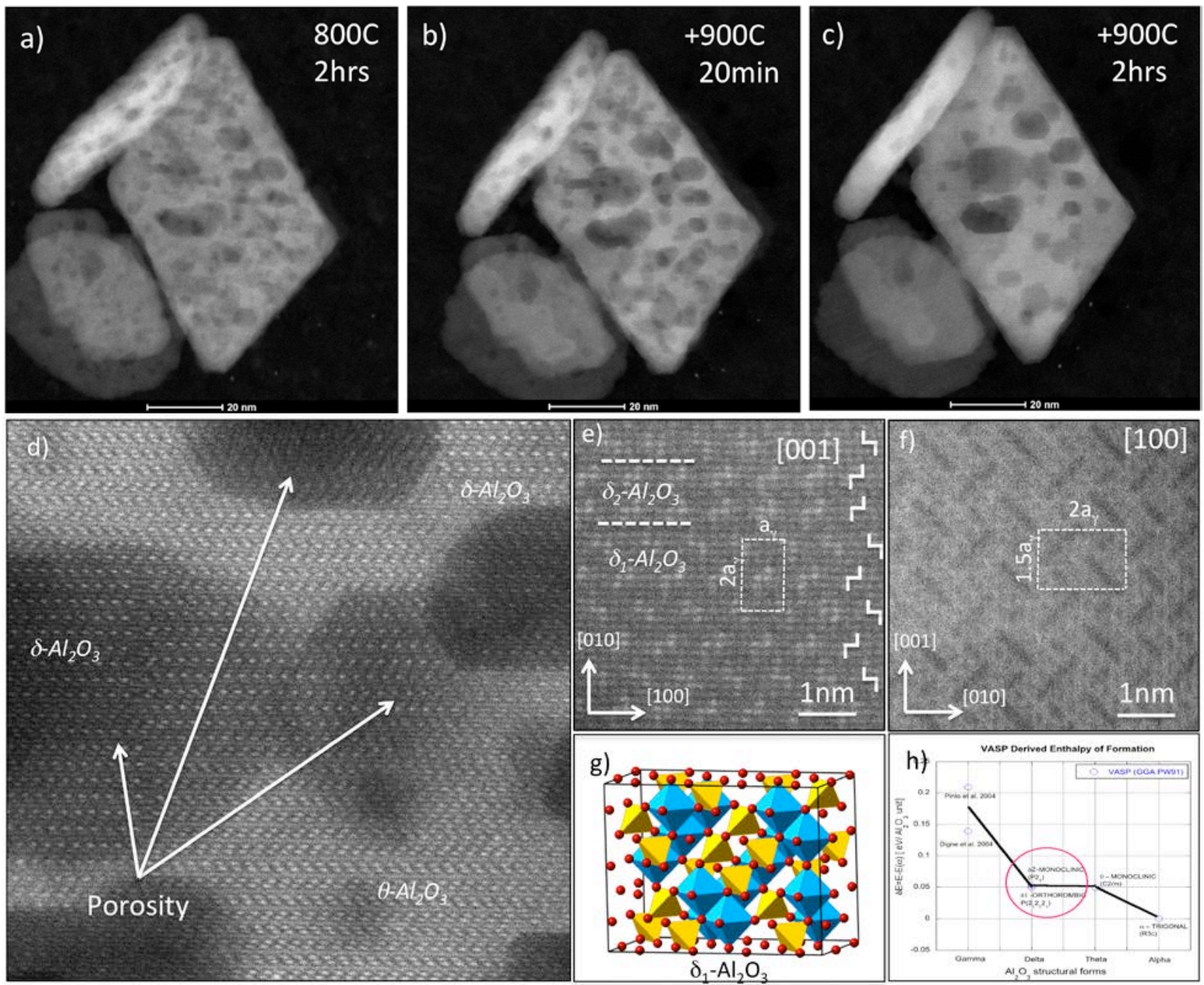

$[100]$

Figure 1. (a,b,c) HAADF observation of microstructural evolution of transition $\mathrm{Al}_{2} \mathrm{O}_{3}$ during insitu heat treatment. (d) HAADF image depicting the domains of $\delta-\mathrm{Al}_{2} \mathrm{O}_{3}$ and $\theta-\mathrm{Al}_{2} \mathrm{O}_{3}$ in a common intergrowth $\left(2 \mathrm{hr} @ 900^{\circ} \mathrm{C}\right),(\mathrm{e}, \mathrm{f})$ Atomic level depiction of $\delta_{1}-\mathrm{Al}_{2} \mathrm{O}_{3}$ along [001] and [100] crystallographic directions. (d) Schematic representation of $\delta_{1}-\mathrm{Al}_{2} \mathrm{O}_{3}$. (e) Comparison of enthalpies of formation for the newly derived $\delta-\mathrm{Al}_{2} \mathrm{O}_{3}$ and other relevant $\mathrm{Al}_{2} \mathrm{O}_{3}$ [3]. 